\title{
CLIMATOLOGIA DO SERTÃo DA PARAÍBA, BRASIL
}

\author{
Isa Gabriela Delgado de Araújo ${ }^{(a)}$, Marco Tulio Mendonça Diniz ${ }^{(b)}$, Flávia Luana Dantas ${ }^{(c)}$, \\ Fernando Eduardo Borges da Silva ${ }^{(d)}$
}

(a) Departamento de Geografia/Centro de Ensino Superior do Seridó, Universidade Federal do Rio Grande do Norte, isiiinhad@hotmail.com

(b) Departamento de Geografia/Centro de Ensino Superior do Seridó, Universidade Federal do Rio Grande do Norte, tuliogeografia@gmail.com

(c) Departamento de Geografia/Centro de Ensino Superior do Seridó, Universidade Federal do Rio Grande do Norte, flavia.dantas@outlook.com

(d) Departamento de Geografia/Centro de Ensino Superior do Seridó, Universidade Federal do Rio Grande do Norte, fernando100borges00.1@gmail.com

\section{Eixo: Climatologia em diferentes níveis escalares: mudanças e variabilidades}

\section{Resumo}

A classificação climática visa abranger grandes áreas e analisar todas as suas condições no meio, seja elas climáticas ou biogeográficas. As transformações na climatologia geográfica começaram a ocorrer a partir da década de 1960 principalmente por Monteiro. Uma das principais metodologias empregadas para identificar os tipos de clima é o trabalho de Nímer (1979) juntamente com a equipe do IBGE, associando métodos tradicionais a métodos dinâmicos, classificando em climas zonais e regionais. O objeto de estudo (Sertão da Paraíba) apresentou resultados influenciados pelo relevo, pois quanto mais afastados estão os postos pluviométricos do Planalto da Borborema, mais altos tendem a serem os valores de precipitação. O objetivo geral da pesquisa é realizar a classificação dos sistemas atmosféricos atuantes e propor um mapeamento de tipos de clima para o Sertão da Paraíba, que é uma etapa de um projeto maior de mapeamento de todo o Estado da Paraíba.

Palavras chave: Classificação, relevo, Sertão da Paraíba.

\section{Introdução}

A classificação climática tende a identificar uma grande área ou região, zonas com características climáticas e biogeográficas relativamente homogêneas viabilizando indicação valiosa sobre as condições ecológicas, as potencialidades agrícolas e o meio ambiente da região (ANDRADE JÚNIOR et al., 2005).

As transformações na Climatologia Geográfica começaram a ser idealizadas desde os anos de 1960 por autores como Monteiro (1962, 1964), que visava à implantação de um caráter genético à classificação climática (MONTEIRO, 1962). Logo depois, Nímer e a sua equipe no Instituto Brasileiro de Geografia e Estatística (IBGE) apresentaram um modelo metodológico de classificação de climas embasado na "necessidade de conjugar métodos tradicionais a métodos dinâmicos" (NÍMER, p.75, 1979), conjugando uma classificação genético-dinâmica de climas zonais e regionais. 
Segundo Diniz e Pereira (2015) as propostas de Nímer e Monteiro apresentam semelhança em considerar a atuação dos sistemas atmosféricos como fator fundamental nos tipos de clima, mas diferem na questão das normais do clima, pois o primeiro considerava fundamental e o segundo substituiu pela análise rítmica, retratando anos padrão e não o período de 30 anos da normal do clima.

A nova classificação de climas feita por Nímer (1979) é utilizada oficialmente pelo IBGE e é referência para todos os estudiosos da climatologia geográfica (DINIZ; PEREIRA, 2015). Nesta referência cita-se Mendonça e Danni-Oliveira (2007) que utilizaram a mesma configuração adotada pelo IBGE.

A produção da climatologia do estado da Paraíba (PB) em escala regional não é tão significativa, portanto, surge à necessidade de propor inicialmente um novo modelo de classificação climática para o Sertão Paraibano, baseado na estrutura feita por Nímer (1979), assim como foi feito para o estado do Rio Grande do Norte pelos autores Diniz e Pereira (2015).

O Estado da Paraíba apresenta trabalhos de classificação climática como o de Francisco et. al (2015), mas neste trabalho eles expõe os métodos de Köppen originário da fitossociologia e da ecologia, enfatizando que cada vegetação natural de uma grande região da Terra, exibe o clima existente e o de Thornthwaite destacando a evapotranspiração potencial como método para classificar o clima que são métodos que tratam a climatologia de forma mais estática. Em vista disso, o estudo visa diferenciar deste método, empregando o método de Nímer (1979), associando métodos tradicionais a métodos dinâmicos.

O objetivo geral da pesquisa é realizar a classificação dos sistemas atmosféricos atuantes e propor um mapeamento de tipos de clima para o Sertão da Paraíba, que é uma etapa de um projeto maior de mapeamento de todo o Estado da Paraíba.

\section{Metodologia}

Foi realizado um mapeamento de isoietas e de tipos de clima do Sertão da Paraíba com escala de 1:250.000 com os dados do Departamento de Ciências Atmosféricas - DCA da Universidade Federal de Campina Grande - UFCG (DCA/UFCG, on-line), disponibilizados também pela Sudene (1990).

A pesquisa utilizou a estrutura do modelo metodológico da classificação de climas de Nimer (1979), suporte embasado em três sistemas fundamentais:

Primeiro sistema: é procedente da climatologia dinâmica e fundamentado em padrões de circulação atmosférica. A classificação climática deste sistema é compreendida por climas zonais e regionais. A Paraíba dentro deste contexto integra dois tipos climáticos, Zona Tropical do Nordeste Oriental e Tropical do Nordeste Oriental. 
Segundo sistema: delimita as regiões térmicas, que para Nimer (1979) é firmado em índices de diferentes autores.

Terceiro sistema: delimita as regiões quanto à umidade, baseado na existência ou não de seca e no comprimento médio da estação seca. Para Bagnouls e Gaussen (1953) a definição de seca, é que mês seco é aquele cujo total das precipitações em milímetros é igual ou inferior ao dobro da temperatura média em Graus Celsius $(\mathrm{P} \leq 2 \mathrm{~T})$.

O referencial para classificação das diferenciações climáticas no estado da Paraíba é climas superúmidos (sem ou com secas); úmidos ( 1 a 2 ou 3 meses secos); subúmidos (4 a 5 meses secos) e semiárido (6 ou mais meses secos), o último mencionado é dividido em brando (6 meses secos), mediano ( 7 a 8 meses secos), forte (9 a 10 meses secos) e muito forte (11 meses secos) (NÍMER, 1979).

A normal climatológica utilizada na pesquisa é a de 1961-1990 a mais atual. No trabalho foram utilizados dados de precipitação pluviométrica e temperatura do Departamento de Ciências Atmosféricas - DCA da Universidade Federal de Campina Grande - UFCG (DCA/UFCG, on-line), disponibilizadas na internet. Logo após estes dados são tabulados no software Microsoft Excel 2010, a partir deles é feito os cálculos para determinar a quantidade média de meses secos por ano. Os dados onde foram georreferenciados e analisados em plataforma de Sistema de Informação Geográfica (SIG), no software ArcGIS 10.2.2.

O georreferenciamento é caracterizado como ramo da ciência que estuda o processamento de informações georreferenciadas utilizando aplicativos, que em sua maioria são SIGs, equipamentos, dados de diversas fontes e profissionais especializados. Toda esta estrutura permite a manipulação, avaliação e geração de produtos cartográficos, associados à localização de informações da superfície da Terra (PIROLI, 2010).

O mapeamento de isoietas foi feito a partir dos dados de precipitação, este processo trabalhou com médias mensais e anuais, referente a um período de 30 anos ou mais registros contínuos. O mapeamento de isotermas retrata o campo da temperatura, utilizando dados de temperatura do ar média.

Analisou-se também a geomorfologia do estado da Paraíba, principalmente do sertão paraibano utilizando Shuttle Radar Topography Mission (SRTM), pois o relevo é um fator importante que influencia no decréscimo e aumento de precipitação, assim como na temperatura, áreas a barvalento (úmidas) e sotavento (secas).

\section{Referencial}

\subsection{Sistemas Atmósfericos atuantes na área}


No Sertão da Paraíba, o grande gerador de precipitação em macroescala é a Zona de Convergência Intertropical (ZCIT). Relacionam-se com as Correntes Perturbadas de Norte, citadas por Nimer (1977). Para Molion e Bernardo (2002) esta Zona é descrita como:

(...) uma extensa região de convergência dos ventos Alísios de nordeste, oriundos do sistema de alta pressão ou anticiclone subtropical do HN, e dos ventos Alísios de sudeste, provenientes da alta subtropical do HS. É caracterizada por movimentos ascendentes, baixas pressões, uma banda de nebulosidade e chuvas no sentido leste-oeste aproximadamente (MOLION; BERNARDO, 2002, p. 3).

Conforme Souza (2010), a ZCIT retrata a ascensão do ar quente e úmido, que é derivado da convergência dos ventos alísios, onde a umidade do oceano vai ser deslocada para os altos níveis da troposfera, ocasionando na formação de nuvens.

Sobre o Atlântico Equatorial, a ZCIT varia sua posição média de $14^{\circ} \mathrm{N}$, (posição mais ao norte), com ocorrência no período de agosto-setembro a $2^{\circ} \mathrm{S}$ (posição mais ao sul), com sua atuação máxima de fevereiro a maio. De acordo com Molion e Bernardo (2002), a ZCIT do Atlântico se relaciona diretamente com a circulação geral da atmosfera, a sua migração está estreitamente associada às anomalias de temperatura de sua superfície (ATSM), principalmente em seu lado oeste.

A Temperatura Superficial do Mar (TSM) é determinante para o posicionamento e a intensidade da ZCIT, pois se localiza principalmente onde a TSM é mais elevada. As ATSM positivas (dipolo quente) são caracterizadas quando as águas do Atlântico Norte estão mais quentes do que no Sul, causando ao NEB período de estiagem. Ao contrário do que acontece com a ATSM negativa (dipolo frio), a ZCIT é posicionada no Atlântico Sul, quando suas águas estão mais elevadas que o Norte, contribuindo para precipitação na Região Nordeste (MOLION; BERNARDO, 2002).

Segundo Melo, Cavalcanti e Souza (2009) em anos de El Niño o NEB fica em uma região de subsidência, inibindo a precipitação, devido à associação com os movimentos ascendentes e subsidentes das células de Hadley e de Walker, mecanismos relativos à ATSM.

Além da banda principal da ZCIT, principalmente em anos atípicos, segundo Uvo (1989), há a ocorrência de uma segunda banda convectiva, localizada mais ao Sul da principal, o seu tempo de duração é mais curto e não possui organização climática. A autora retrata que é um fenômeno esporádico, e que sua principal atuação é nos primeiros meses do ano, fevereiro, março e abril.

Outro sistema atuante na área são os VCAN que são um conjunto de nuvens em formato de circulo, girando no sentido horário, onde no seu centro ocorrem os movimentos de ar subsidentes, acarretando a 
inibição de chuvas e aumento de pressão, já na periferia, o ar está em ascensão e gera a formação de nuvens consequentemente a precipitação (FERREIRA; MELLO, 2005).

O seu deslocamento para as latitudes subtropicais é devido à ocorrência de uma forte advecção de ar (transporte de umidade) quente e úmido do flanco leste do vórtice. A convecção, portanto, acontece quando à ligação entre o ar quente e úmido e a frente fria (FERREIRA; RAMÍREZ; GAN, 2009).

No hemisfério sul (HS), especificamente no Brasil, sua atuação é nos meses de dezembro a fevereiro, variando de 4 a 11 dias, as precipitações advindas por meio deste sistema são evidentes quando os VCAN de formam sobre o continente (FERREIRA; RAMÍREZ; GAN, 2009).

Sistema de microescala que ocorre no sertão da PB é a orografia, que tem expressividade. O relevo é considerado neste contexto como uma barreira topográfica para massas de ar migratórias, onde o ar vai ascender sobre a montanha e resfriar, resultando na formação de nuvens estratiformes (CHRISTOPHERSON, 2012).

"Uma barreira orográfica intensifica a atividade de convecção e causa mais ascensão durante a passagem de sistemas frontais e sistemas ciclônicos, extraindo mais umidade das massas de ar em passagem." (CHRISTOPHERSON, p. 211, 2012).

Segundo Christopherson (2012), a umidade condensa na encosta a barlavento da montanha com ascensão de ar tépido e úmido, no sotavento o ar é descendente ocasionando evaporação, tornando-o o ar quente e seco.

\subsection{2 Mapas do $\mathbf{R N}$}

Os autores Diniz e Pereira (2015) realizaram pesquisa com a mesma metodologia para o estado do Rio Grande do Norte, afirmaram que os planaltos potiguares mesmo com altitude modesta exercem papel importante na diminuição e no aumento da precipitação, de acordo com a localização do posto pluviométrico à barlavento ou à sotavento destes planaltos.

Relataram também que quanto mais afastado o posto pluviométrico está da encosta de sotavento da Borborema, maiores tendem a serem as médias de precipitação anual. Tendo como exemplo, Parelhas/RN (no sopé da encosta ocidental da Borborema Potiguar - $561 \mathrm{~mm} / \mathrm{ano}$ ), Jardim do Seridó/RN (571,4 mm/ano), Caicó/RN (684,4 mm/ano), São Fernando/RN (765,5 mm/ano) e Jardim de Piranhas/RN (794,5 $\mathrm{mm} / \mathrm{ano})$. 

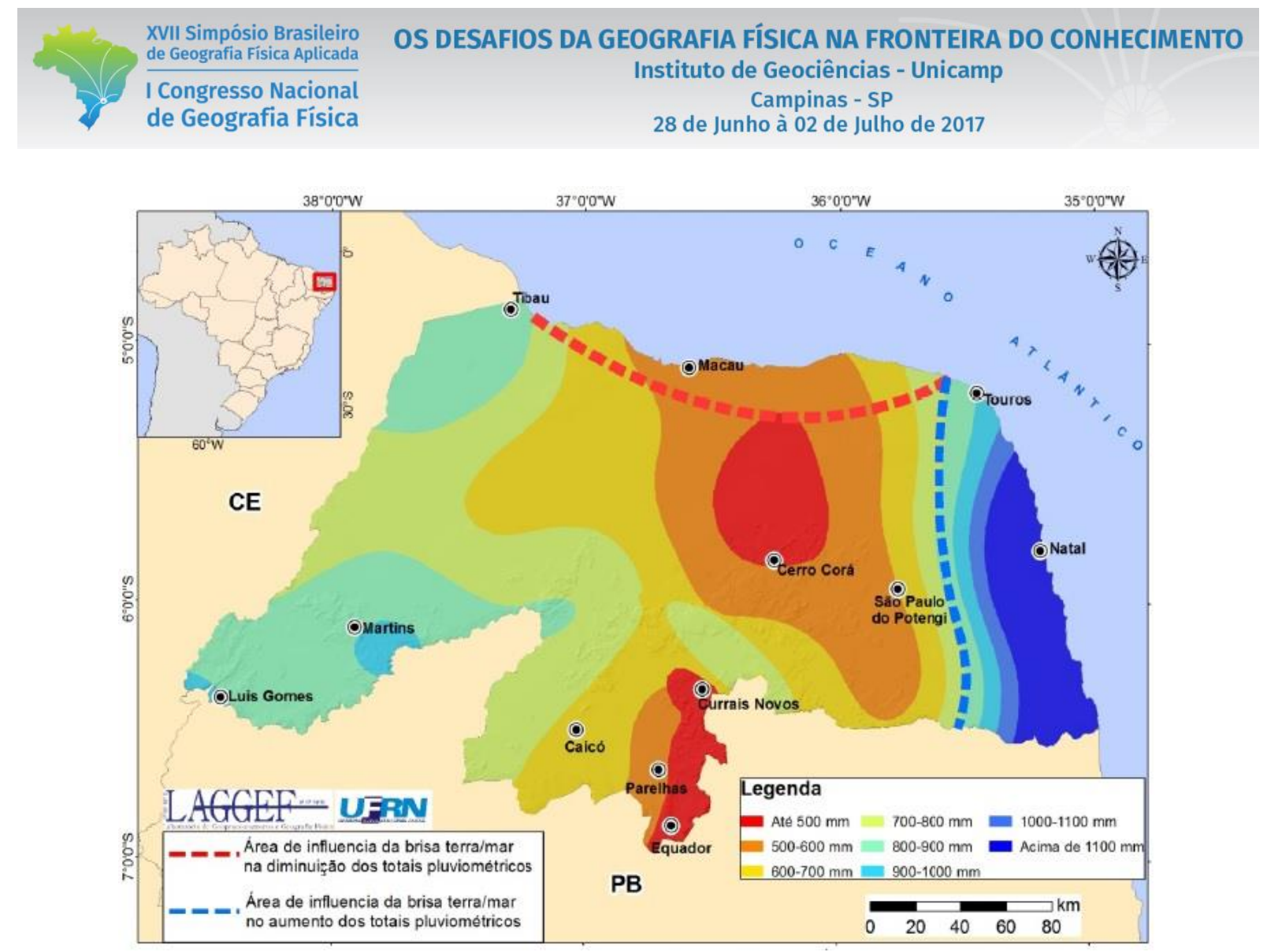

Figura 1 - Mapa de Isoietas do Rio Grande do Norte.

Fonte: Sudene (1990). Adaptado por Diniz e Pereira (2015).

Os tipos de clima do RN (Figura 2) foram caracterizados como Clima Tropical do Nordeste Oriental e Tropical de Zona Equatorial. A capital Natal está inserida no primeiro tipo climático citado anteriormente retratando uma realidade de subdomínio úmido, com apenas 3 meses secos. A estação chuvosa se prolonga de janeiro até setembro, o trimestre mais chuvoso é nos meses de abril a junho, com chuvas de outono-inverno (DINIZ; PEREIRA, 2015). 


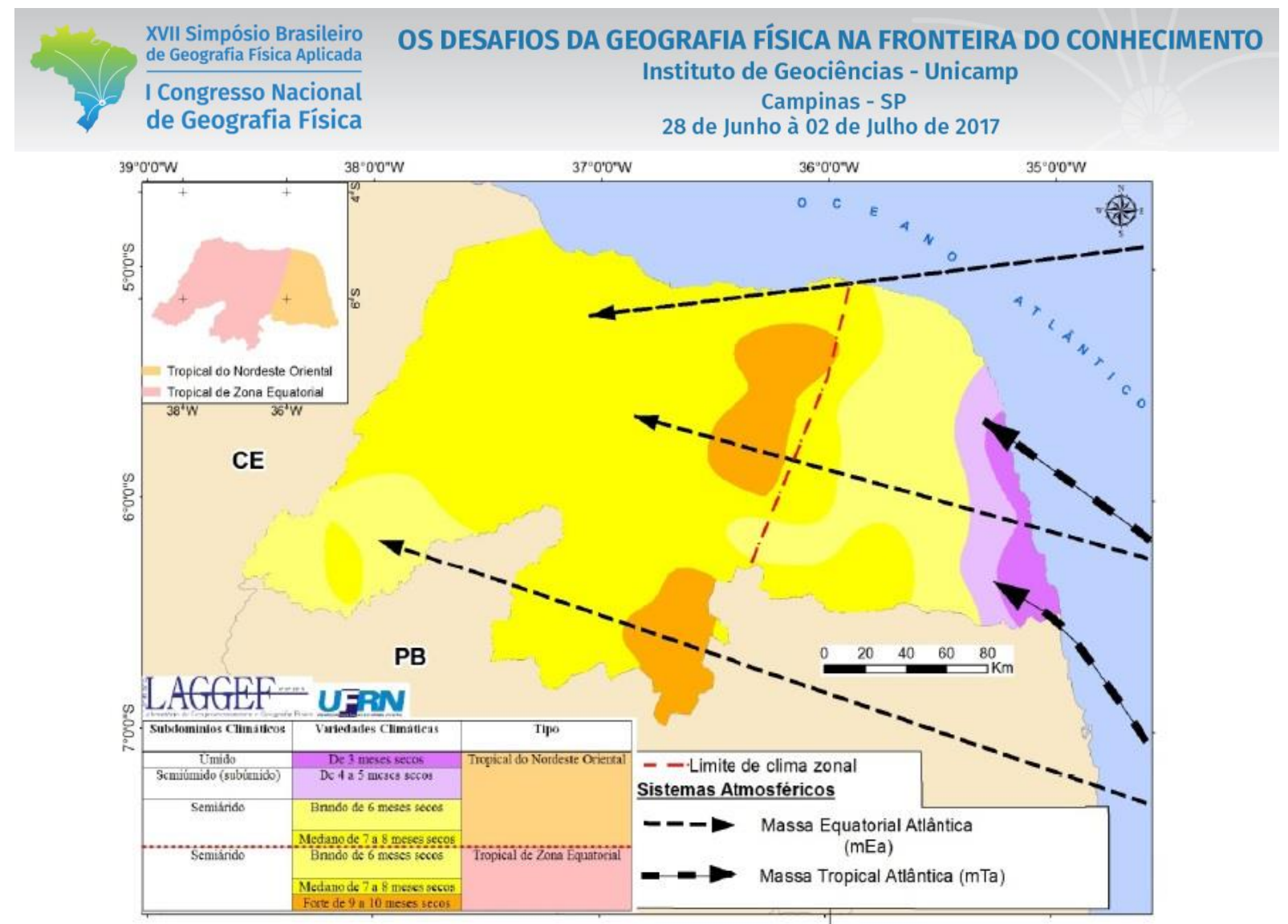

Figura 2 - Mapa de climas do Rio Grande do Norte

Fonte: Sudene (1990) adaptado por Diniz e Pereira (2015).

O Seridó Potiguar se enquadra no subdomínio semiárido com duas variedades climáticas de 7 a 8 meses secos e 9 a 10 meses secos. O município de Currais Novos representa uma área da Borborema de clima semiárido (8 meses secos) e tem curta estação chuvosa de fevereiro a maio, com trimestre mais chuvoso de fevereiro-abril (chuvas de verão-outono), assim como Caicó apresentando 7 meses secos (DINIZ; PEREIRA, 2015).

\section{Resultados}

O Planalto da Borborema influencia o aumento e a diminuição dos totais pluviométricos da Paraíba, este se estende também pelos estados do RN, Pernambuco e Alagoas. O que foi observado no Sertão da Paraíba foi o mesmo que ocorreram para o RN relatado pelos autores Diniz e Pereira (2015). O afastamento dos postos pluviométricos da encosta da Borborema possuem médias anuais maiores do que as que estão próximas.

Próximo à encosta sotavento é notável a afirmação citada anteriormente (Figura 3), como é o caso de Patos (698, 9 mm/ano), Passagem (668, 2 mm/ano), Imaculada (683,6 mm/ano) e Manaíra (697,8 $\mathrm{mm} / \mathrm{ano}$ ). Afastado pouco mais do planalto nota-se a precipitação mais elevada, tendo como exemplo os 


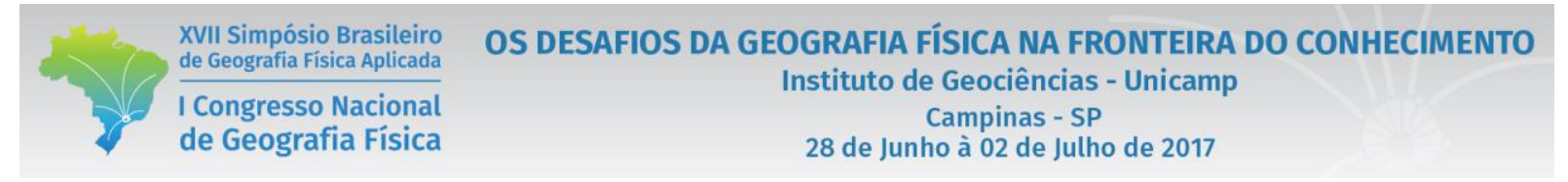

municípios de Bom Jesus (865,1 mm/ano), Cajazeiras (891,8 mm/ano), São José de Piranhas (980,5 $\mathrm{mm} / \mathrm{ano})$ e Aguiar $(902,9 \mathrm{~mm} / \mathrm{ano})$.

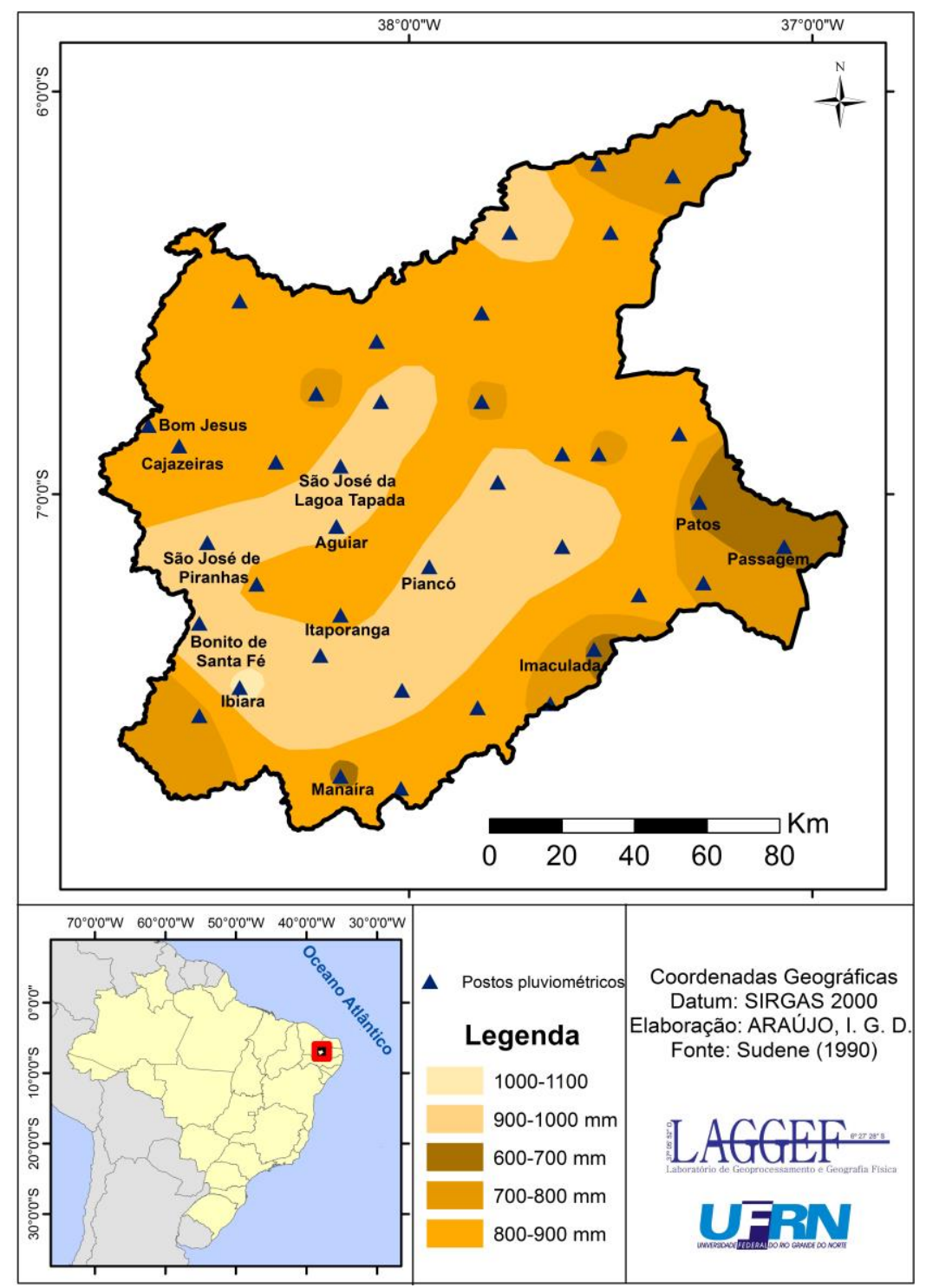

Figura 3 - Mapa de isoietas do Sertão da Paraíba

Fonte: Sudene (1990) adaptada pelos autores.

A Região Metropolitana do Vale do Piancó apresenta as maiores precipitações do Sertão Paraibano, e possui duas microrregiões importantes: a cidade de Piancó $(915,7$ mm/ano) e Itaporanga (876,3 mm/ano) que estão inseridas na Bacia Piancó-Piranhas-Açu. Os valores elevados foram observados nas cidades de Ibiara (1.040 mm/ano), Bonito de Santa Fé (974,2 mm/ano), São José de Piranhas (980,5 mm/ano) e São José da Lagoa Tapada (993,7 mm/ano). 
O clima do Sertão da PB é caracterizado por ser Tropical de Zona Equatorial que define o subdomínio climático semiárido e apresenta duas estações: uma seca e outra chuvosa, influenciada principalmente pela ZCIT.

O diferencial do Sertão da Paraíba para o do Rio Grande do Norte é que a estação chuvosa do sertão paraibano, em média se inicia logo no mês de janeiro, enquanto que no Rio Grande do Norte se inicia a estação chuvosa apenas em fevereiro, com chuvas de verão-outono em ambos. Atuam no sertão paraibano sistemas atmosféricos de oeste. Isso se deve ao avanço da Massa Equatorial Continental (MEC) até a Borborema e a Chapada da Diamantina no mês de janeiro, o que fornece mais umidade à ZCIT na região (NÍMER, 1989).

A massa de ar é basicamente um corpo de ar com determinada temperatura, pressão e umidade. Portanto a MEC é um corpo de ar úmido e quente que contribui com umidade diretamente para ZCIT, que retira o ar seco do Nordeste, principalmente no sul do Ceará e na Paraíba e isto faz com que ocorram as chuvas primeiro nestas áreas, pois a ZCIT é atraída pela umidade (NÍMER, 1989).

O subdomínio climático do sertão da Paraíba é semiárido com variedades climáticas variando de 6 a 7-8 meses secos. As temperaturas reais são elevadas, principalmente no primeiro quadrimestre, período chuvoso da região.

\section{Considerações finais}

Defrontando com os resultados obtidos para o estado do RN, o Sertão da Paraíba apresentou semelhanças e diferenças significativas. A similaridade entre eles se dá pelo fato da influência do relevo, pois quanto mais afastados se encontram os postos pluviométricos do Planalto da Borborema, as precipitações tendem a serem maiores e os municípios próximos consequentemente são caracterizados como secos.

A diferença exposta entre os dois estados é considerável, pois no Sertão da Paraíba o período chuvoso é influenciado pela Massa Equatorial Continental, que avança sobre o Nordeste e possibilita assim, chuvas a partir do mês de janeiro (chuvas verão-outono), resultado da atração da umidade imposta pela MEC no Nordeste para o principal sistema atmosférico da região que é a ZCIT.

\section{Referências Bibliográficas}

ANDRADE JUNIOR, A. S. et al. Classificação climática e regionalização do semi-árido do Estado do Piauí sob cenários pluviométricos distintos. In: Revista Ciência Agronômica, Vol. 36, nº2, 2005.

BAGNOULS, F.; GAUSSEN, H. Saison sècheet indice xérothermique. Bulletin de la Société d'histoire naturelle de Toulouse, Toulouse, n. 88, v.1, 1953. p. 193 - 240.

CHRISTOPHERSON, R. W. Geossistemas. Uma introdução à geografia física. 7. ed. Porto Alegre: Bookman, 2012. 
DCA/UFCG. Departamento de Ciências Atmosféricas (DCA) - Universidade Federal de Campina Grande (UFCG). Clima. Campina Grande, s.d.. Disponível em: 〈http://www.dca.ufcg.edu.br/clima/>. Acesso em: 05 jan. 2017.

DINIZ, M. T. M; PEREIRA, V. H. C. CLIMATOLOGIA DO ESTADO DO RIO GRANDE DO NORTE, BRASIL: SISTEMAS ATMOSFÉRICOS ATUANTES E MAPEAMENTO DE TIPOS DE CLIMA. Boletim Goiano de Geografia. Goiânia, v. 35, n. 3, p. 488-506, set./dez. 2015.

FERREIRA, Antônio Geraldo; MELLO, Namir Giovanni da Silva. PRINCIPAIS SISTEMAS ATMOSFÉRICOS ATUANTES SOBRE A REGIÃO NORDESTE DO BRASIL E A INFLUÊNCIA DOS OCEANOS PACÍfICO E ATLÂNTICO NO CLIMA DA REGIÃO. Revista Brasileira de Climatologia. Vol. 1, No ${ }^{\circ}$. Dezembro - 2005.

FERREIRA, Nelson J.; RAMÍREZ, Maria Valverde; GAN, Manoel Alonso.VÓRTICES CICLÔNICOS DE ALTOS NÍVEIS QUE ATUAM NA VIZINHANÇA DO NORDESTE DO BRASIL. In: Cavalcanti, I. F. A. et al. (Org.). Tempo e Clima no Brasil. São Paulo: Oficina de Texto, 2009.

FRANCISCO, P. R. M.; MEDEIROS, R. M. de; SANTOS, D.; MATOS, R. M. de. Classificação Climática de Köppen e Thornthwaite para o Estado da Paraíba. Revista Brasileira de Geografia Física, 2015, n.04.

MELO, A. B. C.; CAVAlCANTI, I. F de A.; SOUZA, P. P. Zona de Convergência Intertropical do Atlântico. In: CAVALCANTI, I. F. A.; FERREIRA, N. J.; SILVA, M. G. A. J.; DIAS, M. A. F. S. (Org.). Tempo e Clima no Brasil. São Paulo: Oficina de Textos, 2009. p. 26-42.

MENDONÇA, F.; DANNI-OLIVEIRA, I. M. Climatologia: noções básicas e climas do Brasil. São Paulo: Oficina de Textos, 2007.

MOLION, L. C. B.; BERNARDO, S. O. Uma revisão da dinâmica das chuvas no nordeste brasileiro. Revista Brasileira de Meteorologia, Rio de Janeiro, v. 17, n. 1, 2002. p. 1-10.

MONTEIRO, C. A. F. Da necessidade de um caráter genético a classificação climática. Revista Geográfica, v. 31, n. 57, 1962. p. 29-44.

MONTEIRO, C. A. F. Sobre um índice de participação das massas de ar e sua aplicabilidade à classificação climática. Revista Geográfica, v. 33, n. 61, 1964. p. 55-69.

NÍMER, E. Clima. In: BRASIL. Instituto Brasileiro de Geografia e Estatística. Geografia do Brasil: Região Nordeste. Rio de Janeiro: IBGE, 1977.

NÍMER, E. Um Modelo Metodológico da Classificação de Climas. Revista Brasileira de Geografia, v. 41 n. 4, 1979. p. 59-89.

NIMER, E. Climatologia do Brasil. 2.ed. Rio de Janeiro: Fundação IBGE, 1989.

PIROLI, E.L. Introdução ao geoprocessamento. Ourinhos: Campus Experimental UNESP, 2010.

SOUZA, Antônio José da Silva. EVENTOS EXTREMOS DE PRECIPITAÇÃO NO LESTE DA AMAZÔNIA. Dissertação de mestrado apresentado ao Instituto de Ciências Atmosféricas da Universidade Federal de Alagoas, Alagoas, 2010. 110 p.

SUDENE. Dados pluviométricos mensais do Nordeste. Recife, 1990.

UVO, C.R.B., 1989. A Zona de Convergência Intertropical (ZCIT) e sua Relação com a Precipitação da Região Norte do Nordeste Brasileiro. Dissertação de Mestrado em Meteorologia, Instituto Nacional de Pesquisas Espaciais, São José dos Campos, SP. 